\title{
A Study of Intramolecular Hydrogen Bonding in Levoglucosan Derivatives
}

\author{
Lucas Quiquempoix ${ }^{1}$, Elena Bogdan ${ }^{2}$, Neil J. Wells ${ }^{1}$, Jean-Yves Le Questel ${ }^{2, *}$, Jérôme Graton ${ }^{2, *}$ \\ and Bruno Linclau ${ }^{1, *}$ \\ 1 Chemistry, University of Southampton, Highfield, Southampton SO17 1BJ, UK, lq1d13@soton.ac.uk (L.Q.); \\ n.j.wells@soton.ac.uk (N.J.W.) \\ 2 CEISAM UMR CNRS 6230, Faculté des Sciences et des Techniques, Université de Nantes, 2 rue de la \\ Houssinière-BP 92208, 44322 Nantes CEDEX 3, France; elena_bogdan@hotmail.fr \\ * Correspondence: jean-yves.le-questel@univ-nantes.fr (J.-Y.L.Q.); jerome.graton@univ-nantes.fr (J.G.); \\ bruno.linclau@soton.ac.uk (B.L.); Tel.: +33-2-76-64-51-68 (J.G.)
}

Academic Editor: Steve Scheiner

Received: 30 January 2017; Accepted: 21 March 2017; Published: 24 March 2017

\begin{abstract}
Organofluorine is a weak hydrogen-bond (HB) acceptor. Bernet et al. have demonstrated its capability to perturb $\mathrm{OH} \cdots \mathrm{O}$ intramolecular hydrogen bonds (IMHBs), using conformationally rigid carbohydrate scaffolds including levoglucosan derivatives. These investigations are supplemented here by experimental and theoretical studies involving six new levoglucosan derivatives, and complement the findings of Bernet et al. However, it is shown that conformational analysis is instrumental in interpreting the experimental data, due to the occurrence of non-intramolecular hydrogen-bonded populations which, although minor, cannot be neglected and appears surprisingly significant. The DFT conformational analysis, together with the computation of NMR parameters (coupling constants and chemical shifts) and wavefunction analyses (AIM, NBO), provides a full picture. Thus, for all compounds, the most stabilized structures show the $\mathrm{OH}$ groups in a conformation allowing IMHB with O5 and O6, when possible. Furthermore, the combined approach points out the occurrence of various IMHBs and the effect of the chemical modulations on their features. Thus, two-center or three-center IMHB interactions are observed in these compounds, depending on the presence or absence of additional HB acceptors, such as methoxy or fluorine.
\end{abstract}

Keywords: hydrogen bond; intramolecular interaction; NMR coupling constants; quantum calculations; fluorination; levoglucosan

\section{Introduction}

Hydrogen bonding (H-bonding) to organic fluorine (C-F) represents a very weak interaction [1,2]. Given bioactive compounds typically contain stronger oxygen and/or nitrogen $(\mathrm{O} / \mathrm{N})$ based hydrogen-bond (HB) acceptor atoms, intra- or intermolecular HB formation, in solution or in the solid phase, will preferentially involve these groups over a C-F group. The same applies for polar protic solvents (including water). This has been amply demonstrated by crystal structure analysis of fluorinated compounds, where $\mathrm{O} / \mathrm{N}$-based $\mathrm{HB}$ donors typically form intramolecular (IM) hydrogen bonds with $\mathrm{O} / \mathrm{N}$ based $\mathrm{HB}$ acceptors instead of with fluorine, even when the molecule in question contains many fluorine atoms [3,4]. This effect can lead to interesting crystal packing structures, featuring different molecular conformations in the unit cell in order to maximize, say, $\mathrm{OH} \cdots \mathrm{O}$, at the expense of $\mathrm{OH} \cdots \mathrm{F}$ interactions [5].

However, in the absence of competing HB acceptors, alcohol groups have shown to form intramolecular HBs with fluorine groups. First described by Biamonte and Vasella [6], many groups have now reported such $\mathrm{OH} \cdots \mathrm{F}$ IMHBs through the observation of an OH-F coupling constant 
( $\left.{ }^{1} \mathrm{H}-\mathrm{NMR}\right)[1,7]$. The vast majority of these cases involve conformationally constrained systems, though the occurrence of $\mathrm{OH} \cdots \mathrm{F}$ IMHB have recently been demonstrated in acyclic fluorohydrins [8].

In this framework, an interesting and relevant challenge is to determine whether existing hydrogen bonds present in a molecule can be influenced by the HB accepting properties of fluorine. This has been elegantly investigated by Bernet and Vasella through NMR-analysis of a set of rigid 4-fluorinated levoglucosan derivatives, by using the ${ }^{3} \mathrm{~J}_{\mathrm{H}-\mathrm{OH}}$ value to deduce the dihedral angle revealing positional information of the alcohol hydrogen (NMR spectra taken in $\mathrm{CDCl}_{3}$ ) [9]. For example (Figure 1a-c), in the 4-deoxy levoglucosan 1 , the ${ }^{3} J_{\mathrm{H} 2-\mathrm{OH}}$ value of $10.2 \mathrm{~Hz}$ indicates that the $\mathrm{OH}$ is directed towards the $\mathrm{O} 5$ acetal oxygen because of IM H-bonding. When a fluorine atom is positioned at $\mathrm{C} 4$, as in $\mathbf{2}$, this value increases to $11.5 \mathrm{~Hz}$, indicating a larger $\mathrm{H} 2-\mathrm{OH}$ dihedral angle. This is explained by the axial fluorine group competing with $\mathrm{O} 5$ for hydrogen bonding to the $\mathrm{OH}$, causing a shift in the $\mathrm{OH}$ position. The observed ${ }^{\mathrm{h} 1} \mathrm{~J}_{\mathrm{F}-\mathrm{OH}}$ value corroborates this explanation. Interestingly, in 3 , the $\mathrm{OH} \cdots \mathrm{F}$ distance is increased compared to 2 , as evidenced by smaller ${ }^{\mathrm{h} 1} J_{\mathrm{F}-\mathrm{OH}}$ value, which had been explained by the increased electron withdrawing effect of the acetate group (compared to an $\mathrm{OH}$-group that acts as $\mathrm{HB}$ donor), resulting in the fluorine becoming a poorer HB acceptor. By using this methodology on 4-fluorinated and 4,4-difluorinated 4-deoxymannose derivatives, Bernet and Gouverneur could nicely demonstrate that fluorine as part of a $\mathrm{CF}_{2}$ group is a worse $\mathrm{HB}$ acceptor than when part of a $\mathrm{CHF}$ moiety (not shown) [10], in agreement with measurements of intermolecular $\mathrm{OH} \cdots \mathrm{F}$ interactions [11]. Interestingly, Widmalm et al. reported a study of 2-deoxy-2-fluorolevoglucosan 4 (Figure 1d), which has a similar IMHB arrangement as $\mathbf{2} / \mathbf{3}$, but for which no ${ }^{\mathrm{h} 1} \mathrm{~J}_{\mathrm{F}-\mathrm{OH}}$ coupling could be observed [12]. This was also explained by the decreased HB accepting capacity of the fluorine group due to the antiperiplanar C-O6 group. This is despite the ${ }^{3} J_{\mathrm{H} 4, \mathrm{OH}}$ value in 4 is identical to the ${ }^{3} \mathrm{~J}_{\mathrm{H} 2, \mathrm{OH}}$ value in 3 .

(a)

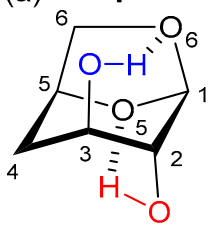

$\delta_{\mathrm{OH} 2} 2.10 \mathrm{ppm}$

${ }^{3} J_{\mathrm{H} 2, \mathrm{OH}} 10.2 \mathrm{~Hz}$

$\delta_{\mathrm{OH} 3} 2.52 \mathrm{ppm}$

${ }^{3} \mathrm{~J}_{\mathrm{H} 3, \mathrm{OH}} 7.8 \mathrm{~Hz}$

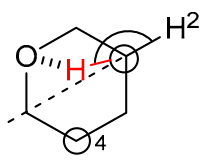

(H) (b)

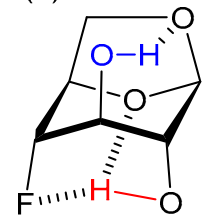

$\delta_{\mathrm{OH} 2} 2.33 \mathrm{ppm}$

${ }^{3} J_{\mathrm{H} 2, \mathrm{OH}} 11.5 \mathrm{~Hz}$

${ }^{\mathrm{h}} 1 \mathrm{~J}_{\mathrm{F}, \mathrm{OH} 2} 1.8 \mathrm{~Hz}$

$\delta_{\mathrm{OH} 3} 2.39 \mathrm{ppm}$

${ }^{3} \mathrm{~J}_{\mathrm{H} 3, \mathrm{OH}} 7.4 \mathrm{~Hz}$

${ }^{4} J_{\mathrm{F}, \mathrm{OH} 3} 0.8 \mathrm{~Hz}$

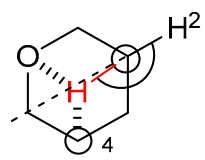

(F) (c) 3

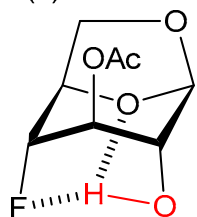

$\delta_{\mathrm{OH} 2} 2.57 \mathrm{ppm}$

${ }^{3} \mathrm{~J}_{\mathrm{H} 2, \mathrm{OH}} 10.3 \mathrm{~Hz}$

${ }^{\mathrm{h}} 1 \mathrm{~J}_{\mathrm{F}, \mathrm{OH} 2} 1.2 \mathrm{~Hz}$

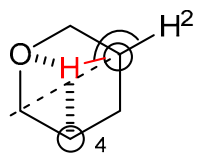

(F) (d) 4

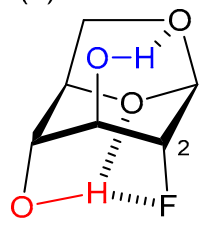

$\delta_{\mathrm{OH} 4} 2.49 \mathrm{ppm}$

${ }^{3} J_{\mathrm{H} 4, \mathrm{OH}} 10.4 \mathrm{~Hz}$

${ }^{\mathrm{h} 1} \mathrm{~J}_{\mathrm{F}, \mathrm{OH} 4}-$

$\delta_{\mathrm{OH} 3} 2.07 \mathrm{ppm}$

${ }^{3} \mathrm{~J}_{\mathrm{H} 3, \mathrm{OH}} 6.3 \mathrm{~Hz}$

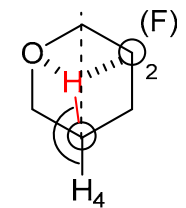

Figure 1. Selected precedence involving intramolecular $\mathrm{OH} \cdots \mathrm{F}$ hydrogen bonding.

It has been shown that these weak interactions can affect properties such as intermolecular hydrogen bond donating capacity [13] and reactivity [6] of alcohols, and conformational properties of acyclic alcohols [8]. Given the importance of inter- and intramolecular hydrogen bonding and conformation in many areas $[14,15]$, the study of these weak interactions, and the factors that influence them, is of interest.

In the current work, we have selected levoglucosan derivatives 4-9 (Figure 2) to expand the study of intramolecular hydrogen bonding properties. The substrate pairs $4 / 5$ and $7 / 8$ allow studying the perturbation of the OH4 $\cdots$ O5 IMHB by F, while $\mathbf{6}$ allows to compare the effect of F with OMe. For 4-6 we also noticed interesting substituent effects affecting the $\mathrm{OH} 3 \cdots \mathrm{O} 6 \mathrm{IMHB}$, and substrate 9 was also 
included in this context. The computational calculations usefully complemented the experimental results by showing that structural analyses based on ${ }^{\mathrm{h} 1} \mathrm{JOH}_{\mathrm{OHF}}$ and ${ }^{3} \mathrm{~J}_{\mathrm{H}, \mathrm{OH}}$ coupling constants have to be carefully interpreted in combination with theoretical studies, given the population of the IM H-bonded conformers is in some cases far from $100 \%$. In addition, estimated IMHB distances and strengths were available through computational calculations.

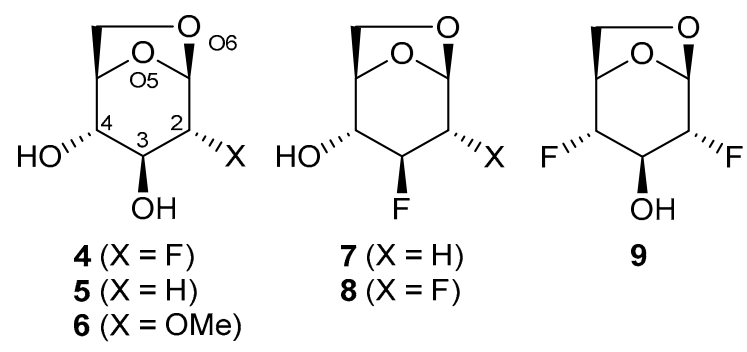

Figure 2. Structures of levoglucosan derivatives used in this study.

\section{Results}

\subsection{Synthesis of the Levoglucosan Derivatives}

Levoglucosan derivatives 5 [16], 7, and 8 [17] were obtained by hydrogenolysis using Pearlman's catalyst of the known $\mathbf{1 0}$ [18], $\mathbf{1 2}$ [18], and $\mathbf{1 3}[17,18]$ in excellent yields while $\mathbf{6}$ [19] was obtained in a two steps sequence methylation-hydrogenolysis of the known 11 [20] (Scheme 1). The known compounds $4[12,21]$ and $9[21,22]$ were obtained as described.<smiles>O[C@H]1CC2CO[C@@H](C2)[C@H]1Br</smiles>

10<smiles>O[C@@H]1O[C@@H]2OC[C@H]2[C@H]1Cc1ccccc1</smiles>

11<smiles>[X]C1C(F)[C@H](O)C2CO[C@@H]1O2</smiles>

$12(X=H)$

$13(X=F)$

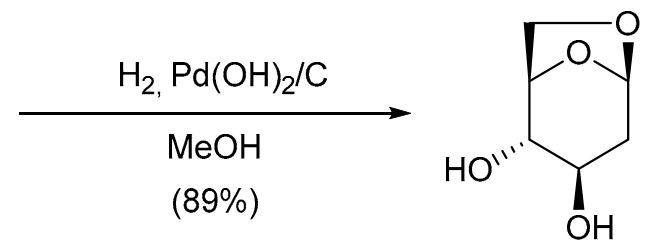

5<smiles>CO[C@H](O)[C@@H]1[C@H]2OC[C@H](O2)[C@H](O)[C@H]1O</smiles>

6

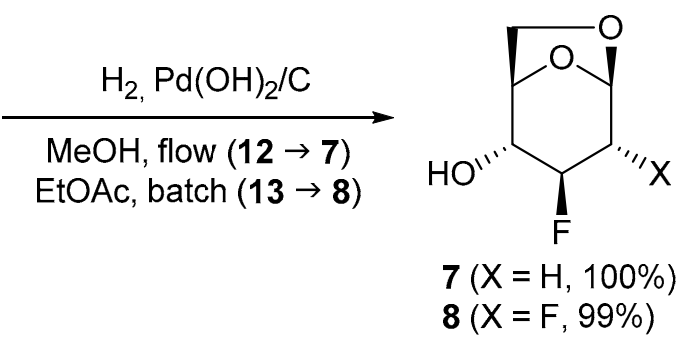

Scheme 1. Synthesis of the novel levoglucosan derivatives. 


\subsection{Experimental and Theoretical NMR Features}

The measurement of the NMR spectra was carried out under carefully controlled anhydrous conditions in dilute chloroform solution (solute concentration between 7-19 mM) at $25{ }^{\circ} \mathrm{C}$. The summary of the chemical shift and coupling constant values is given in Table 1. The data were collected such that the digital resolution was $0.05 \mathrm{~Hz} /$ point. Interestingly, a control experiment in which a $7.5 \mathrm{mM}$ solution of 4 was spiked with 1 equiv of $\mathrm{H}_{2} \mathrm{O}$ showed no change in the ${ }^{3} \mathrm{JOH}_{\mathrm{OH}}$ and ${ }^{\mathrm{h} 1} \mathrm{~J}_{\mathrm{OH}-\mathrm{F}}$ values (see supporting information).

Table 1. Experimental and theoretical NMR features of the $\mathrm{OH} 4$ and $\mathrm{OH} 3$ hydroxyl groups in compounds 4-9.

\begin{tabular}{|c|c|c|c|c|c|c|c|c|c|c|}
\hline \multirow{2}{*}{ Compound } & \multicolumn{2}{|c|}{${ }^{3} J_{\mathrm{H} 4, \mathrm{OH}}(\mathrm{Hz})$} & \multicolumn{2}{|c|}{$\delta_{\mathrm{OH} 4}(\mathrm{ppm})$} & \multicolumn{2}{|c|}{${ }^{\mathrm{h} 1} J_{\mathrm{OH} \cdots \mathrm{F}}(\mathrm{Hz})$} & \multicolumn{2}{|c|}{${ }^{3} J_{\mathrm{H} 3, \mathrm{OH}}(\mathrm{Hz})$} & \multicolumn{2}{|c|}{$\delta_{\mathrm{OH} 3}(\mathrm{ppm})$} \\
\hline & $\operatorname{Exp}$ & Calc $^{1}$ & Exp & Calc $^{1}$ & Exp & Calc $^{1}$ & Exp & Calc $^{1}$ & Exp & Calc $^{1}$ \\
\hline 5 & 9.5 & 12.0 & 2.29 & 2.20 & - & - & 7.5 & 9.0 & 2.56 & 2.68 \\
\hline 4 & 10.9 & 12.9 & 2.58 & 2.46 & 1.4 & 0.9 & 6.4 & 7.7 & 2.15 & 2.04 \\
\hline 6 & 11.6 & 13.2 & 2.88 & 2.77 & $\mathrm{v}$ & - & 7.7 & 8.9 & 2.40 & 2.48 \\
\hline 7 & 9.9 & 10.7 & 2.39 & 2.29 & - & - & - & - & - & - \\
\hline 8 & 11.3 & 12.6 & 2.60 & 2.50 & 0.8 & 0.3 & - & - & - & - \\
\hline 9 & - & - & - & - & - & - & 6.1 & 7.7 & 2.30 & 1.99 \\
\hline
\end{tabular}

${ }^{1}$ Theoretical parameters are calculated at the IEF-PCM/B97-2/pcJ-2//B97-D3 ${ }^{\text {BJ }} / 6-311++G(2 d, p)$ level of theory in $\mathrm{CHCl}_{3}$ at $25^{\circ} \mathrm{C}$.

The theoretical coupling constant and chemical shift values involving the levoglucosan's $\mathrm{OH} 3$ and $\mathrm{OH} 4$ hydroxyl groups have been computed at the B97-2/pcJ-2 level, on geometries optimized at the B97-D3 ${ }^{\mathrm{BJ}} / 6-311++\mathrm{G}(2 \mathrm{~d}, \mathrm{p})$ level in chloroform at $25^{\circ} \mathrm{C}$ (discussed below). These computed parameters correspond to the weighting of the individual values calculated for each conformer by their respective relative populations according to Equation (1) in the Materials and Methods section, and are also shown in Table 1. It is important to note that the calculated ${ }^{3} J$ coupling constants are systematically overestimated compared to the experimental data. Nevertheless, the relative experimental and theoretical trends are on the whole consistent. Thus, regarding the chemical shift values order, a perfect agreement with the observed $\delta_{\mathrm{OH} 4}$ is obtained, with the ranking $5<7<4<8<6$. For the $\delta_{\mathrm{OH} 3}$ values, the theoretical results confirm the behavior $5>6>4$, but not for 9 , where a weaker theoretical value is computed.

\subsection{Conformational Analysis of the Levoglucosans}

Observed $J$ values are averaged over the populations of the possible conformers. For the compounds under study, the identified degrees of freedom are the rotation around the $\mathrm{C}-\mathrm{O}$ bonds of the hydroxyl groups, and of the methoxy group in $\mathbf{6}$. Hence, when comparing coupling constants between molecules, the relative population of the relevant conformers needs to be considered. The conformers are defined by their values of the $\varphi_{\mathrm{HCOH}}$ dihedral angles: trans $(t)$ if $\varphi_{\mathrm{HCOH}} \sim 180^{\circ}$, gauche $(g)$ when $\varphi_{\mathrm{HCOH}} \sim 60^{\circ}$, and gauche(-) (g-) when $\varphi_{\mathrm{HCOH}} \sim-60^{\circ}$, and similarly for the $\varphi_{\mathrm{HCOC}}$ dihedral angle for the methoxy group. For example, the notation $t_{-} g-g$ depicts a trans orientation around the $\mathrm{C}-4$ bond, a gauche(-) conformation around the C-3 bond and finally a gauche orientation around the C-2 bond. The whole dataset is reported in the Supplementary Materials, and a summary of the most important conformers involving $\mathrm{OH} 4$ is given in Table 2, and of $\mathrm{OH} 3$ in Table 3. Figure 3 illustrates typical geometries encountered with the various conformations around the $\mathrm{OH} 4$ and $\mathrm{OH} 3$ hydroxyl groups. For all structures, the $t_{-} t$ forms are systematically the most stabilized conformers meaning that both hydroxyl moieties are involved in $\mathrm{OH} \cdots \mathrm{O}$ intramolecular interactions. 
Table 2. Theoretical features ${ }^{1}$ of the levoglucosan conformations featuring the $\mathrm{OH} 4$ group in compounds $4-8$.

\begin{tabular}{|c|c|c|c|c|c|c|c|c|}
\hline \multicolumn{2}{|c|}{ Conformer $^{2}$} & \multirow{2}{*}{$\frac{\left.G \mathbf{( k J} \cdot \mathbf{m o l}^{-\mathbf{1}}\right)}{0.0}$} & \multirow{2}{*}{$\begin{array}{l}p_{i}(\mathbf{\%}) \\
65.2 \%\end{array}$} & \multirow{2}{*}{$\frac{d_{\mathrm{OH} 4 \cdots \mathrm{O} 5}(\AA)}{2.377}$} & \multirow{2}{*}{$\frac{d_{\mathrm{OH} 4 \cdots \mathrm{X} 2(\mathrm{ax})}(\AA)}{-}$} & \multirow{2}{*}{$\frac{\mathrm{HO} 4 \mathrm{CH}^{\left({ }^{\circ}\right)}}{165.0}$} & \multirow{2}{*}{$\frac{{ }^{3} \mathrm{~J}_{\mathrm{OH} 4-\mathrm{H}}(\mathbf{H z})}{13.6}$} & \multirow{2}{*}{$\frac{\delta_{\mathrm{OH} 4}(\mathrm{ppm})}{2.31}$} \\
\hline \multirow{7}{*}{5} & $t_{-} t$ & & & & & & & \\
\hline & $t \_g$ & 3.8 & $14.0 \%$ & 2.324 & - & 164.2 & 13.5 & 2.49 \\
\hline & $t \_g-$ & 5.4 & $7.5 \%$ & 2.319 & - & 163.7 & 13.2 & 2.53 \\
\hline & $g-\_t$ & 5.5 & $7.0 \%$ & - & - & -56.7 & 3.0 & 1.31 \\
\hline & $g_{-} t$ & 6.1 & $5.5 \%$ & - & - & 68.7 & 0.8 & 1.05 \\
\hline & $g-g-$ & 12.2 & $0.5 \%$ & - & - & 76.0 & -0.2 & 1.05 \\
\hline & $g_{-}^{-} g_{-}^{-}$ & 13.4 & $0.3 \%$ & - & - & -60.2 & 2.8 & 1.24 \\
\hline \multirow{9}{*}{4} & $t \_t$ & 0.0 & $49.8 \%$ & 2.465 & 2.595 & 175.0 & 13.8 & 2.49 \\
\hline & $t \_g$ & 1.8 & $23.7 \%$ & 2.388 & 2.802 & 170.8 & 13.7 & 2.62 \\
\hline & $t \_g-$ & 2.2 & $20.2 \%$ & 2.386 & 2.782 & 170.7 & 13.4 & 2.61 \\
\hline & $g-\_t$ & 8.4 & $1.7 \%$ & - & - & -60.1 & 1.7 & 1.34 \\
\hline & $g_{-} t$ & 8.8 & $1.4 \%$ & - & - & 65.3 & 0.9 & 1.08 \\
\hline & $g-g$ & 9.5 & $1.1 \%$ & - & - & 67.5 & 0.6 & 1.04 \\
\hline & $g-g$ & 10.1 & $0.9 \%$ & - & - & -57.1 & 2.2 & 1.36 \\
\hline & $g \_g-$ & 10.2 & $0.8 \%$ & - & - & -54.5 & -0.1 & 1.07 \\
\hline & $g^{-}-g^{-}$ & 11.5 & $0.5 \%$ & - & - & -58.2 & 1.2 & 1.29 \\
\hline \multirow{10}{*}{6} & $t \_t \_g$ & 0.0 & $48.1 \%$ & 2.511 & 2.384 & -176.4 & 13.4 & 2.83 \\
\hline & $t_{-} t_{-} g-$ & 1.8 & $23.7 \%$ & 2.539 & 2.324 & -174.1 & 13.3 & 2.88 \\
\hline & $t \_g-g$ & 4.1 & $9.2 \%$ & 2.408 & 2.627 & 176.3 & 13.6 & 2.66 \\
\hline & $t_{-} g-g$ & 4.5 & $7.8 \%$ & 2.413 & 2.603 & 177.1 & 13.4 & 2.69 \\
\hline & $t_{-g}-g-$ & 5.5 & $5.2 \%$ & 2.431 & 2.578 & 178.6 & 13.7 & 2.65 \\
\hline & $t_{-} g_{-}-g_{-}$ & 5.7 & $4.8 \%$ & 2.425 & 2.588 & 178.0 & 13.4 & 2.65 \\
\hline & $g-\_t \_g$ & 11.4 & $0.5 \%$ & - & - & -64.1 & 1.1 & 1.14 \\
\hline & $g_{-} t_{-} g_{-}$ & 12.8 & $0.3 \%$ & - & - & -67.2 & 0.7 & 1.10 \\
\hline & $g_{-} t_{-} g_{-}$ & 12.9 & $0.3 \%$ & - & - & 67.0 & 0.7 & 0.97 \\
\hline & $g \_t g$ & 13.3 & $0.2 \%$ & - & - & 67.1 & 0.6 & 0.93 \\
\hline \multirow{3}{*}{7} & $t$ & 0.0 & $82.9 \%$ & 2.321 & - & 163.4 & 12.6 & 2.50 \\
\hline & $g$ & 5.2 & $10.0 \%$ & - & - & 77.9 & -0.3 & 1.11 \\
\hline & $g-$ & 6.1 & $7.1 \%$ & - & - & -49.3 & 3.4 & 1.49 \\
\hline \multirow{3}{*}{8} & $t$ & 0.0 & $92.6 \%$ & 2.390 & 2.840 & 169.5 & 13.5 & 2.60 \\
\hline & $g$ & 7.6 & $4.3 \%$ & - & - & 68.9 & 0.6 & 1.18 \\
\hline & $g-$ & 8.4 & $3.1 \%$ & - & - & -52.6 & 2.9 & 1.54 \\
\hline
\end{tabular}

${ }^{1}$ Theoretical parameters are calculated at the IEF-PCM/B97-D3 ${ }^{\mathrm{BJ}} / 6-311++\mathrm{G}(2 \mathrm{~d}, \mathrm{p})$ level of theory in $\mathrm{CHCl}_{3}$ at $25{ }^{\circ} \mathrm{C} .{ }^{2}$ The first descriptor refers to $\mathrm{H}-\mathrm{C} 4-\mathrm{O} 4-\mathrm{H}$, the second descriptor to $\mathrm{H}-\mathrm{C} 3-\mathrm{O} 3-\mathrm{H}$, and the last descriptor to the $\mathrm{H}-\mathrm{C} 2-\mathrm{O} 2-\mathrm{CH}_{3}$ torsion angle.

(a)

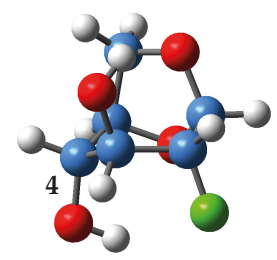

$4 t_{-} t$

(b)

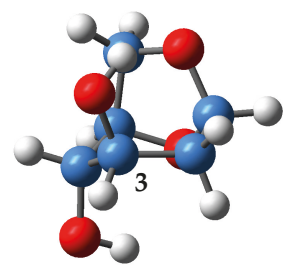

5 t_t

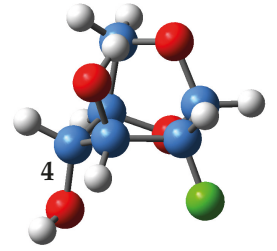

$4 g^{-} \_t$

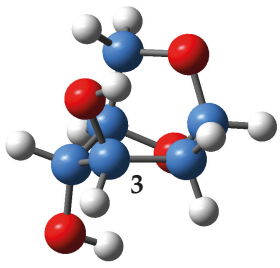

$5+g$

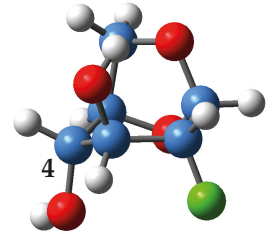

$4 g_{-} t$

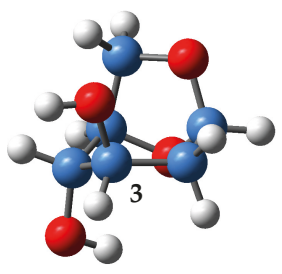

5 t_g-

Figure 3. Examples of optimized structures of (a) levoglucosan 4, with the OH4 group in $t, g-$, and $g$ orientation; (b) levoglucosan 5, with the $\mathrm{OH} 3$ group in $t, g$ and $g$ - orientation. 
Table 3. Theoretical features ${ }^{1}$ of the levoglucosan conformations featuring the $\mathrm{OH} 3$ group in compounds 4-6, 9.

\begin{tabular}{|c|c|c|c|c|c|c|c|}
\hline \multicolumn{2}{|c|}{ Conformer $^{2}$} & \multirow{2}{*}{$\frac{G\left(\mathbf{k J} \cdot \mathbf{m o l}^{-\mathbf{1}}\right)}{0.0}$} & \multirow{2}{*}{$\begin{array}{l}p_{i}(\%) \\
65.2 \%\end{array}$} & \multirow{2}{*}{$\frac{d_{\mathrm{OH} 3 \cdots \mathrm{O} 6}(\AA)}{2.122}$} & \multirow{2}{*}{$\frac{\mathrm{HO}^{\mathrm{CH}}\left(^{\circ}\right)}{156.9}$} & \multirow{2}{*}{$\frac{{ }^{3} \mathrm{JOH}_{\mathrm{OH}}(\mathbf{H z})}{11.0}$} & \multirow{2}{*}{$\frac{\delta_{\mathrm{OH} 3}(\mathrm{ppm})}{3.15}$} \\
\hline \multirow{7}{*}{5} & $t \_t$ & & & & & & \\
\hline & $t \_g$ & 3.8 & $14.0 \%$ & - & 81.6 & -0.2 & 0.74 \\
\hline & $t \_g-$ & 5.4 & $7.5 \%$ & - & -50.8 & 3.9 & 1.33 \\
\hline & $g-\_t$ & 5.5 & $7.0 \%$ & 2.109 & 158.2 & 11.1 & 3.34 \\
\hline & $g_{-} t$ & 6.1 & $5.5 \%$ & 2.116 & 158.2 & 11.3 & 3.26 \\
\hline & $g \_g-$ & 12.2 & $0.5 \%$ & - & 76.0 & 4.0 & 1.21 \\
\hline & $g-g-$ & 13.4 & $0.3 \%$ & - & -60.2 & 3.5 & 1.20 \\
\hline \multirow{9}{*}{4} & $t_{-} t$ & 0.0 & $49.8 \%$ & 2.136 & 158.5 & 12.0 & 2.66 \\
\hline & $t g$ & 1.8 & $23.7 \%$ & - & 60.4 & 1.7 & 1.20 \\
\hline & $t_{-} g-$ & 2.2 & $20.2 \%$ & - & -50.1 & 4.1 & 1.56 \\
\hline & $g-\_t$ & 8.4 & $1.7 \%$ & 2.169 & 159.8 & 12.2 & 2.59 \\
\hline & $g_{-} t$ & 8.8 & $1.4 \%$ & 2.185 & 160.6 & 12.6 & 2.47 \\
\hline & $g \_g$ & 9.5 & $1.1 \%$ & - & 62.2 & 1.5 & 1.14 \\
\hline & $\begin{array}{l}0-0 \\
g-g\end{array}$ & 10.1 & $0.9 \%$ & - & 64.4 & 1.0 & 1.15 \\
\hline & $g-g-$ & 10.2 & $0.8 \%$ & - & -54.5 & 3.2 & 1.39 \\
\hline & $g_{-}-g-$ & 11.5 & $0.5 \%$ & - & -58.2 & 2.6 & 1.36 \\
\hline \multirow{10}{*}{6} & $t \_t \_g$ & 0.0 & $48.1 \%$ & 2.094 & 158.4 & 11.5 & 2.97 \\
\hline & $t \_t \_g-$ & 1.8 & $23.7 \%$ & 2.078 & 157.6 & 11.7 & 3.07 \\
\hline & $t \_-g$ & 4.1 & $9.2 \%$ & - & 77.1 & -0.3 & 0.77 \\
\hline & $t \_g-g$ & 4.5 & $7.8 \%$ & - & -52.2 & 3.2 & 1.35 \\
\hline & $t \_g_{-} g_{-}$ & 5.5 & $5.2 \%$ & - & 68.8 & 0.5 & 0.98 \\
\hline & $t_{-} g_{-} g_{-}$ & 5.7 & $4.8 \%$ & - & -51.8 & 3.4 & 1.34 \\
\hline & $g-\_t-g$ & 11.4 & $0.5 \%$ & 2.173 & 159.7 & 11.8 & 2.64 \\
\hline & $g-\_t \_g-$ & 12.8 & $0.3 \%$ & 2.138 & 159.0 & 11.9 & 2.80 \\
\hline & $g \_t-g$ & 12.9 & $0.3 \%$ & 2.173 & 160.0 & 12.0 & 2.59 \\
\hline & $g_{-} t_{-} g_{-}$ & 13.3 & $0.2 \%$ & 2.157 & 159.8 & 12.3 & 2.66 \\
\hline \multirow{3}{*}{9} & $t$ & 0.0 & $51.0 \%$ & 2.186 & 160.3 & 12.4 & 2.50 \\
\hline & $g-$ & 1.8 & $24.9 \%$ & - & -48.8 & 4.3 & 1.64 \\
\hline & $g$ & 1.9 & $24.1 \%$ & - & 63.4 & 1.5 & 1.28 \\
\hline
\end{tabular}

\footnotetext{
${ }^{1}$ Theoretical parameters are calculated at the IEF-PCM/B97-D3 ${ }^{\mathrm{BJ}} / 6-311++\mathrm{G}(2 \mathrm{~d}, \mathrm{p})$ level of theory in $\mathrm{CHCl}_{3}$ at $25^{\circ} \mathrm{C}$. ${ }^{2}$ The first descriptor refers to $\mathrm{H}-\mathrm{C} 4-\mathrm{O} 4-\mathrm{H}$, the second descriptor to $\mathrm{H}-\mathrm{C} 3-\mathrm{O} 3-\mathrm{H}$, and the last descriptor to $\mathrm{H}-\mathrm{C} 2-\mathrm{O} 2-\mathrm{CH}_{3}$ torsion angle.
}

\subsection{Levoglucosans Wavefunction Analyses}

AIM wavefunction analyses in the surroundings of the hydroxyl moieties have been performed to compare the different interactions operating in the various levoglucosans and to provide a better understanding of their respective structural features, as illustrated in Table 4. Bond critical points (BCPs) related to six-membered $\mathrm{OH}$... I IMHB interactions were systematically detected, whereas we were not able to find any $\mathrm{BCP}$ along the $\mathrm{OH} 4 \cdots \mathrm{F}$ and the $\mathrm{OH} 4 \cdots \mathrm{O} 5$ interactions. This latter defines a five-membered IMHB motifs and the AIM methodology is known to fail detecting any BCP in these conditions [23-25]. The interaction energies $E_{n \rightarrow \sigma^{*}}^{(2)}$ computed from the NBO analyses pointed out charge transfer from the oxygen or the fluorine lone pairs to the hydroxyl antibonding orbital whatever the IMHB studied, but they clearly show that these interactions are very weak for the five-membered IMHBs, coherent with the AIM trends. 
Table 4. AIM and NBO computed descriptors ${ }^{1}$ of the IMHB conformers of 4-9.

\begin{tabular}{|c|c|c|c|c|c|c|c|c|}
\hline \multicolumn{2}{|c|}{ Conformer } & $\begin{array}{c}E^{(2)}{ }_{n \rightarrow \sigma^{*}} \\
\mathrm{n}_{\mathrm{O} 6} \rightarrow \sigma^{*} \mathrm{OH} 3 \\
\left(\mathrm{~kJ} \cdot \mathrm{mol}^{-1}\right)\end{array}$ & $\begin{array}{l}\rho_{\mathrm{OH} 3 \cdots \mathrm{O} 6} \\
\text { e.bohr }{ }^{-3}\end{array}$ & $\begin{array}{c}E_{\mathrm{HB}} \\
\left(\mathrm{kJ} \cdot \mathrm{mol}^{-1}\right)\end{array}$ & $\begin{array}{c}E^{(2)}{ }_{\mathrm{n} \rightarrow \sigma^{*}} \\
\mathrm{n}_{\mathrm{O} 5} \rightarrow \sigma^{*} \mathrm{OH} 4 \\
\left(\mathrm{~kJ} \cdot \mathrm{mol}^{-1}\right)\end{array}$ & $\begin{array}{c}E^{(2)}{ }_{n \rightarrow \sigma^{*}} \\
\mathrm{n}_{\mathrm{X} 2} \rightarrow \sigma^{*} \mathrm{OHH}^{*} \\
\left(\mathrm{kJJ} \cdot \mathrm{mol}^{-1}\right)\end{array}$ & $\begin{array}{c}\rho_{\mathrm{OH} 4} \ldots \mathrm{OMe}_{\mathrm{OM}} \\
\text { e.bohr }\end{array}$ & $\begin{array}{c}E_{\mathrm{HB}} \\
\left(\mathrm{kJ} \cdot \mathrm{mol}^{-1}\right)\end{array}$ \\
\hline \multirow{5}{*}{4} & $t \_t$ & 11.9 & 0.020 & 20.0 & 1.6 & 0.4 & - & - \\
\hline & $t \_g$ & - & - & - & 2.4 & 0.2 & - & - \\
\hline & $t_{-g} g_{-}$ & - & - & - & 2.4 & 0.3 & - & - \\
\hline & $g_{-}-t$ & 10.5 & 0.018 & 18.5 & - & - & - & - \\
\hline & $g_{-} t$ & 9.7 & 0.018 & 17.9 & - & - & - & - \\
\hline \multirow{5}{*}{5} & $t \_t$ & 12.6 & 0.020 & 20.5 & 2.8 & - & - & - \\
\hline & $t_{g} g$ & - & - & - & 3.5 & - & - & - \\
\hline & $t_{-g} g_{-}$ & - & - & - & 3.6 & - & - & - \\
\hline & $g_{-}^{-} t$ & 13.6 & 0.021 & 21.1 & - & - & - & - \\
\hline & $g_{-} t$ & 13.1 & 0.020 & 20.7 & - & - & - & - \\
\hline \multirow{6}{*}{6} & $t \_t \_g$ & 14.1 & 0.021 & 22.1 & 1.2 & 3.8 & 0.011 & 10.5 \\
\hline & $t \_t \_g-$ & 15.0 & 0.022 & 23.0 & 1.0 & 4.2 & 0.012 & 11.4 \\
\hline & $t \_g-g$ & - & - & - & 2.1 & 0.8 & 0.007 & 7.0 \\
\hline & $t_{-} g-g$ & - & - & - & 2.1 & 1.0 & 0.008 & 7.2 \\
\hline & $t_{-} g_{-} g-$ & - & - & - & 1.9 & 1.1 & 0.008 & 7.2 \\
\hline & $t_{-} g_{-}-g_{-}$ & - & - & - & 2.0 & 1.1 & 0.007 & 7.1 \\
\hline 7 & $t$ & - & - & - & 2.4 & 0.08 & - & - \\
\hline 8 & $t$ & - & - & - & 3.6 & - & - & - \\
\hline 9 & $t$ & 9.7 & 0.018 & 17.9 & - & - & - & - \\
\hline
\end{tabular}

\section{Discussion}

\subsection{Description of the Intramolecular OH4 Interactions}

\subsubsection{IMHB Involving $\mathrm{OH} 4$}

The IMHB features of the OH4 groups of 4-6 are discussed first. As shown in Table 1 and in Figure 4 , the ${ }^{3} \mathrm{OH} 4-\mathrm{H}$ value for 5 , with no $\mathrm{C} 2$ substituent, gradually increases with the incorporation of a fluorine (4) and methoxy group (6) at C2. This can be explained following the arguments used by Bernet et al. [9]: while in 5 there is only IMHB with O5, in 4 and 6 there is a competition between the $\mathrm{O} 5$ atom and the introduced $\mathrm{F}$ or OMe substituents as $\mathrm{HB}$ acceptors for interaction with $\mathrm{OH} 4$. The $\mathrm{OH} 4$ hydrogen atom is therefore positioned further away from O5, leading to a steady increase in $\mathrm{H} 4-\mathrm{OH} 4$ dihedral angle from $\mathbf{5}<\mathbf{4}<\mathbf{6}$, as shown in Figure 4. This is consistent with the increasing experimental ${ }^{3} J_{\mathrm{H} 4-\mathrm{OH}}$ values, which almost reach the maximum coupling constant of $12.5 \mathrm{~Hz}$ expected for an averaged dihedral angle of $180^{\circ}$. It is noted that for $6, \mathrm{OH} 4$ is computed to become closer to the OMe group than to $\mathrm{O} 5$ (change in sign of dihedral angle) in the most stable conformers.

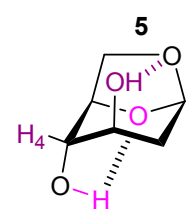

$\delta_{\mathrm{OH} 4} 2.29 \mathrm{ppm}(2.20)$
${ }^{3} J_{\mathrm{H} 4 \mathrm{OH}} 9.5 \mathrm{~Hz}(12.0)$

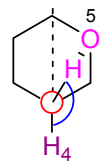

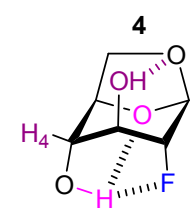

$2.58 \mathrm{ppm}(2.46)$ $10.9 \mathrm{~Hz}(12.9)$

${ }^{\mathrm{h} 1} \mathrm{~J}_{\mathrm{OH}-\mathrm{F}} 1.3 \mathrm{~Hz}(0.9)$

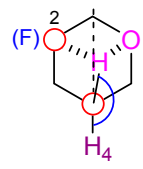

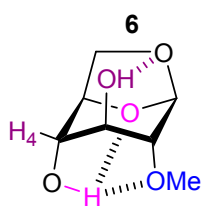

$2.88 \mathrm{ppm}$ (2.77) 11.6 Hz (13.4)

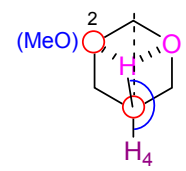

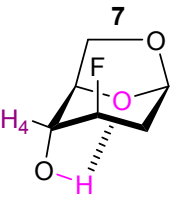

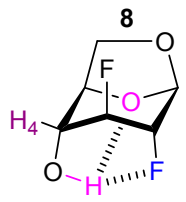

$2.39 \mathrm{ppm}(2.29)$ $9.9 \mathrm{~Hz}(10.7)$

$2.60 \mathrm{ppm}$ (2.50)

$11.3 \mathrm{~Hz}(12.6)$

$0.8 \mathrm{~Hz}(0.3)$

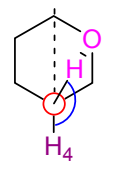

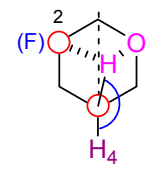

Figure 4. NMR features of the $\mathrm{OH} 4$ surroundings in compounds $\mathbf{4 - 8}$. The theoretical data are given in parentheses. 
These findings are corroborated by the calculated intramolecular distances involving $\mathrm{OH} 4$, and by the NBO interaction energies. The shift in IMHB from $\mathrm{O} 5$ to $\mathrm{F} 2$ and $\mathrm{OMe} 2$ is reflected in an increase in $\mathrm{d}_{\mathrm{OH} 4 \cdots \mathrm{O} 5}$ distances (see Table 2) from $5<\mathbf{4}<\mathbf{6}$. The NBO interaction energies $E^{(2)}{ }_{n \rightarrow \sigma^{*}}$ which correspond to the charge transfer from the $\mathrm{O} 5$ lone pair to the $\mathrm{OH} 4$ antibonding orbital $\left(\mathrm{n}_{\mathrm{O} 5} \rightarrow \sigma^{*} \mathrm{OH} 4\right)$, concomitantly decrease from $\mathbf{5}>\mathbf{4}>\mathbf{6}$ (Table 4), demonstrating the decrease of the efficiency of this charge transfer when a competing acceptor is present at C2. Correspondingly, the NBO interaction energies involving $\mathrm{OH} 4$ and the substituent at $\mathrm{C} 2$ increase going from fluorine to methoxy. This is consistent with the worse $\mathrm{HB}$ acceptor ability of fluorine compared to oxygen. Interestingly, the $\mathrm{NBO}$ interaction energies involving the $\mathrm{OH} 4$ group in 4 also show that the interaction with $\mathrm{O} 5$ is still stronger than the interaction with F2. This is supported by the AIM analyses, for which we only found BCPs between the $\mathrm{OH} 4$ and methoxy substituents in 6, with weak electron densities (from 0.007 to $0.012 \mathrm{e} \cdot \mathrm{bohr}^{-3}$ ) typical of a HB interaction. The $E_{\mathrm{HB}}$ parameter, calculated from the potential energy density $V_{\mathrm{bcp}}$ and ranging from 7 to $11 \mathrm{~kJ} \cdot \mathrm{mol}^{-1}$ for this compound, also indicates a weak IMHB interaction. Conversely, we never observed any $\mathrm{BCP}$ between the hydroxyl group and the fluorine atom for the relevant conformers of 4 (and 8). In fact, one can notice that the interaction with the fluorine atom in the $t_{-} t_{1} t_{-} g$, and $t_{-} g$ - conformations of 4 is longer than the sum of the fluorine and hydrogen van der Waals radii $(2.57 \AA)$ [26]. This intramolecular interaction would, hence, be too long to be considered as an IMHB, but it is clearly an attractive interaction significant enough to slightly weaken the $\mathrm{OH} 4 \cdots \mathrm{O} 5 \mathrm{IMHB}$, and to result in a ${ }^{\mathrm{h} 1} \mathrm{~J}_{\mathrm{OH}-\mathrm{F}}$ coupling.

The chemical shift value of $\mathrm{OH}$ groups is also an indicator of the extent of intramolecular hydrogen bonding. However, the situation described here is a special case as a shift in IMHB from one atom (O5) to other substituents is occurring. Nevertheless, the data show that $\mathrm{H} 4$ becomes progressively more deshielded when it is involved in three-centered IMHB $(5<\mathbf{4}<\mathbf{6})$, with $\delta_{\mathrm{OH} 4}$ being correlated with the ${ }^{3} \mathrm{JOH}_{\mathrm{O}-\mathrm{H}}$ value.

Finally, the computed features for $\mathbf{7}$ and $\mathbf{8}$ show that the $\mathrm{C} 3$ fluorine atom has an equivalent effect on the $\mathrm{OH} 4 \cdots \mathrm{O} 5 \mathrm{IMHB}$ than an $\mathrm{OH} 3$ hydroxyl group, but only when $\mathrm{OH} 3$ is not $\mathrm{H}$-bonded to $\mathrm{O} 6$ (Table 2). Hence, for the $t_{-} g$ forms of 5 and 4 , the OH4 $\cdots$ O5 distances, the dihedral angles and the corresponding $\mathrm{OH} 4$ chemical shifts are all similar. Since the $t_{-} t$ conformers exhibit lower $\delta_{\mathrm{OH} 4}$ values, the higher experimental (averaged) $\delta_{\mathrm{OH} 4}$ values of $\mathbf{7}$ and $\mathbf{8}$ with respect to 5 and $\mathbf{4}$, are explained by the higher population of $t \_t$ conformers of the latter.

Small through space ${ }^{\mathrm{h} 1} J_{\mathrm{OH} 4 \cdots \mathrm{F}}$ couplings were observed in both 2-fluorinated compounds 4 and $\mathbf{8}$ (1.4 and $0.8 \mathrm{~Hz}$, respectively), not detected by Widmalm et al [12] in the NMR spectra of 4 . The smaller ${ }^{\mathrm{h} 1} \mathrm{~J}_{\mathrm{OH} 4 \cdots \mathrm{F}}$ for 8 indicates a longer averaged $\mathrm{OH} 4 \cdots \mathrm{F} 2$ distance. Indeed, if they show similar amounts of IMHB conformers (Table 2), 8 is calculated to exhibit a OH4 $\cdots$ F2 distance (2.840 $\AA$ ) larger than 4 (2.688 $\AA$, weighted value).

Hence, the observation from Bernet that vicinal dihedral angles are a good indicator to reveal IMHB is confirmed here. However, for compound 5, the $\mathrm{OH} 4$ trans conformers are only found to represent $87 \%$ of the whole population (see Table 2 ) and, $13 \%$ of the $\mathrm{OH} 4$ conformers involve a gauche $\mathrm{OH} 4$ dihedral angle for which the ${ }^{3} \mathrm{~J}_{\mathrm{OH} 4-\mathrm{H}}$ values are much lower. This is obviously reflected in the experimental (averaged) ${ }^{3} J_{\mathrm{OH} 4-\mathrm{H}}$ value, and also in the $\delta_{\mathrm{OH} 4}$ value $(2.29 / 2.20 \mathrm{ppm}$, experimental/calculated, compared to the calculated values (2.31-2.53 ppm) of the $\mathrm{OH} 4 t$ conformers, Table 2). With axial fluorination at the $\mathrm{C} 2$ position as in 4 , the $\mathrm{OH} 4$ trans conformation is more favored than in 5, the corresponding total population reaching $94 \%$, and with a methoxy group at $\mathrm{C} 2$, as in 6, almost $99 \%$ of the conformations display an $\mathrm{OH} 4$ trans orientation. Hence, the increase of the individual ${ }^{3} \mathrm{~J}_{\mathrm{OH} 4-\mathrm{H}}$ coupling constants for these trans conformations does not solely originate from the perturbation of OH4-O5 IMHB by $\mathrm{C} 2$-substituents (taking the $\mathrm{OH} 4$ away from $\mathrm{O}$ ), but also from the higher population of the OH4-trans conformers as $\mathrm{C} 2$ is substituted by $\mathrm{F}$ and OMe.

Finally, it was investigated whether the levoglucosan pyranosyl ring featured differences in conformation when different substituents are present, which could be a factor influencing the IMHB features and vice versa. However, overlays of the equivalent conformers of compounds 4, 5, and 6 
(see Supporting Information) show that root mean square deviations computed for the superposition are not higher than $0.013 \AA$ (considering either the pyranosyl or the five-membered C6-bridge ring as reference). This shows that the substituent on the $\mathrm{C} 2$ atom does not significantly affect the levoglucosan scaffold when the two IMHB interactions (OH4 ‥ 2 2 and $\mathrm{OH} 3 \cdots \mathrm{O} 5)$ occur.

\subsubsection{Interplay between $\mathrm{OH} 3$ Features and $\mathrm{IMHB}$ Involving $\mathrm{OH} 4$}

Interestingly, for 4-6, the conformation of the OH3 group, which is not involved in the OH4-O5 $\mathrm{IMHB}$, has an indirect but significant influence on the shortening of the $\mathrm{d}_{\mathrm{OH} 4 \cdots \mathrm{O} 5}$ distance when the $\mathrm{OH} 3$ group is gauche ( $t_{-} g$ and $t_{-} g_{-}$) compared to the trans $\left(t_{-} t\right)$. This leads to a higher calculated $\delta_{\mathrm{OH} 4}$ chemical shift, but has no significant influence on the dihedral angle or on the ${ }^{3} J_{\mathrm{H} 4-\mathrm{OH}}$ value. This effect affects the IMHB features. In 4, when the OH3 group is trans, the OH4-O5 interaction is weaker (longer $\mathrm{d}_{\mathrm{OH} 4 \cdots \mathrm{O}}$ ) compared to the gauche $\mathrm{OH} 3$ conformers, which thus leads to an increase of the $\varphi_{\mathrm{HC}} 4 \mathrm{OH}$ value, favoring the $\mathrm{OH} \cdots \mathrm{F}$ interaction. Indeed, this is consistent with a reduction of the inductive effect of the $\mathrm{OH} 3$ group when it is acting as an $\mathrm{H}$-bond donor, leading to a more electron-rich fluorine atom. In tandem, the $\mathrm{O} 6$ electron withdrawing effect is strengthened with the $\mathrm{OH} 3 \cdots \mathrm{O} 6 \mathrm{IMHB}$, resulting in a more electron poor $\mathrm{O} 5$ atom. Additionally, for 6, the $\mathrm{OH} 3$ conformation has a significant impact on the bond distances between $\mathrm{OH} 4$ and $\mathrm{O} 5$ or $\mathrm{O} 2$ (Table 2): the two most stable OH4 conformers ( $t_{-} t_{-} g$ and $t_{-} t_{-} g^{-}$, amounting to $72 \%$ ) in which $\mathrm{OH} 3$ has an IMHB with $\mathrm{O} 6$, show a shorter $\mathrm{d}_{\mathrm{OH}} \cdots \mathrm{OMe}$ distance than the $\mathrm{d}_{\mathrm{OH} 4 \cdots \mathrm{O} 5}$ one, leading to negative $\varphi_{\mathrm{HC}} 4 \mathrm{OH}$ dihedral angles $\left(-176.4^{\circ}\right.$ and $-174.1^{\circ}$, respectively). In the other $\mathrm{OH} 4 \mathrm{IMHB}$ conformers, where the $\mathrm{OH} 3$ group is gauche, the loss of the $\mathrm{OH} 3 \cdots \mathrm{O} 6$ interaction favors the $\mathrm{OH} 4 \cdots \mathrm{O} 5 \mathrm{IMHB}$. This is obviously to the detriment of the $\mathrm{OH} 4 \cdots \mathrm{OMe}$ $\mathrm{IMHB}$, and positive $\varphi_{\mathrm{HC} 4 \mathrm{OH}}$ dihedral angles are measured in this situation (from $176.3^{\circ}$ to $178.6^{\circ}$ ). It is worth noticing that the effect on the individual ${ }^{3} \mathrm{~J}_{\mathrm{OH}}-\mathrm{H}$ coupling constants are not so important, and that from 4 to 6 , these values are almost the same indicating that the differences observed are especially significantly dependent on the population of the $\mathrm{OH} 4$ gauche conformers.

The observations above are corroborated by the increase of the charge transfer for a given compound upon the loss of the OH3 ..O $\mathrm{OMHB}$, reaching, for 5 and 4, the values calculated for 7 and 8 for which no $\mathrm{OH} 3 \cdots \mathrm{O} 6 \mathrm{IMHB}$ can occur. Hence, the NBO analysis confirms that the occurrence of the $\mathrm{OH} 3 \cdots \mathrm{O} 6 \mathrm{IMHB}$ interaction favors the $\mathrm{OH} 4 \cdots \mathrm{F} 2$ interaction. Indeed, in the $t_{-} t$ form of 4, an enhanced $E^{(2)}{ }_{n \rightarrow \sigma^{*}}$ value for OH4 $\cdots \mathrm{F} 2$ and a lowered $E^{(2)} n \rightarrow \sigma^{*}$ value for OH4 $\cdots \mathrm{O} 5$ is calculated with respect to the $t_{-} g$ conformer. This directly affects the individual $\delta_{\mathrm{OH}}$ chemical shifts identified to be significantly dependent of the three-center IMHB interaction. Indeed, $\delta_{\mathrm{OH} 4}$ decreases from the $t_{-} g$

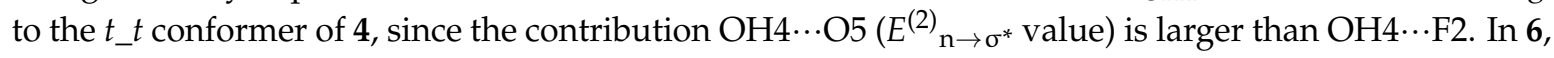
the main contribution is observed for $\mathrm{OH} 4 \cdots \mathrm{OMe}$ rather than for $\mathrm{OH} 4 \cdots \mathrm{O} 5$, and it therefore results to an increase of $\delta_{\mathrm{OH} 4}$ in its $t_{-} g$ forms compared to its $t_{-} t$ conformers.

\subsection{Description of the Intramolecular OH3 Interactions}

The axial $\mathrm{OH} 3$ groups of 4-6, 9 are engaged in $\mathrm{IMHB}$ with $\mathrm{O} 6$, with optimum $\varphi_{\mathrm{HC} 3 \mathrm{OH}}$ dihedral angles for the IMHB conformations of around $157^{\circ}-160^{\circ}$. As a consequence, the experimental coupling constants involving $\mathrm{OH} 3,{ }^{3} \mathrm{~J} \mathrm{OH} 3-\mathrm{H}$ (see Table 1 and Figure 5), are significantly lower than the $\mathrm{OH} 4$ hydroxyl group ones, with values around $7.6 \mathrm{~Hz}$ for compounds 5 and $\mathbf{6}$. Interestingly, for the two deoxyfluorinated derivatives $4(6.4 \mathrm{~Hz})$ and $9(6.1 \mathrm{~Hz})$, a further significant decrease of ${ }^{3} \mathrm{JOH}_{\mathrm{O}-\mathrm{H}}$ is observed despite $\varphi_{\mathrm{HC} 3 \mathrm{OH}}$ dihedral angles very similar to 5 and 6 . Given the OH3 $\cdots$ O6 interaction motif corresponds to a 6-membered IMHB ring, within the AIM methodology, a BCP is systematically detected along this interaction for all these compounds (Table 4). The corresponding electron densities (from 0.018 to $0.022 \mathrm{e} \cdot \mathrm{bohr}^{-3}$ ) and $E_{\mathrm{HB}}$ parameters (from 18 to $23 \mathrm{~kJ} \cdot \mathrm{mol}^{-1}$ ) are much higher than for the $\mathrm{OH} 4 \cdots$ OMe case, and vary in the order of $\mathbf{6}>\mathbf{5}>\mathbf{4}>\mathbf{9}$. In line with these trends, the IMHB distances involving $\mathrm{OH} 3$ decrease following the same order, and the $\delta_{\mathrm{OH} 3}$ chemical shift values of the respective IMHB conformers increase rather similarly $(5>6>4>9$, Table 3). 


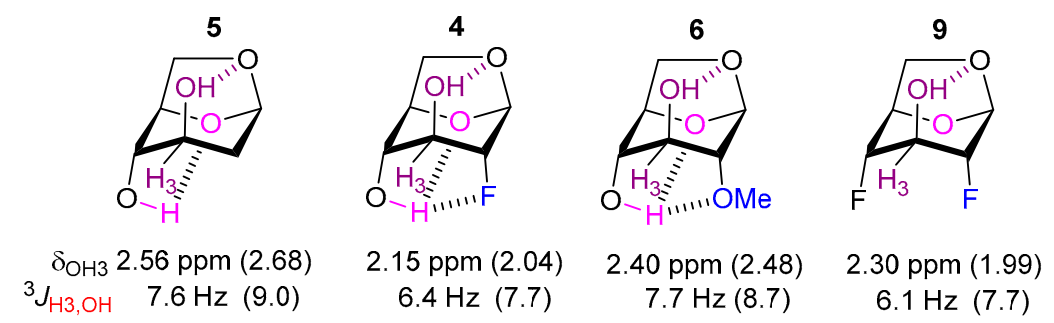

Figure 5. NMR features of the $\mathrm{OH} 3$ surroundings in compounds 4-6, and 9. The theoretical data are given in parenthesis.

Both observations regarding ${ }^{3} \mathrm{JHH}_{\mathrm{OH}-\mathrm{H}}$ and $\delta_{\mathrm{OH} 3}$ variations are difficult to explain by using IMHB arguments only. In contrast, conformational analysis revealed that the IMHB conformations of $\mathrm{OH} 3$ are less stabilized than the IMHB conformations involving $\mathrm{OH} 4$, despite the apparent stronger and shorter IM H-bonds with OH3 (less than $2.2 \AA$, to be compared to more than $2.3 \AA$ for $\mathrm{OH} 4 \mathrm{IMHBs}$ ). Thus, it was found that conformers with $\mathrm{OH} 3 \cdots \mathrm{O} 6 \mathrm{IMHB}$ are significantly less populated $(53 \%, 73 \%$, and $51 \%$ in 4,6 , and 9 , respectively, and $78 \%$ in 5 , in comparison with populations larger than $83 \%$ for IMHB conformers involving $\mathrm{OH} 4)$. The same applies for the $\delta_{\mathrm{OH} 3}$ chemical shifts: the values computed for $\mathrm{OH} 3$ for the IMHB conformers (Table 3) are always larger than the equivalent $\delta_{\mathrm{OH} 4}$ ones (Table 2), in agreement with the greater deshielding of $\mathrm{OH} 3$ because of the stronger interaction. However, since the $\mathrm{OH} 3 \mathrm{IMHB}$ conformers are less stabilized and therefore less represented in the whole set, the average $\delta_{\mathrm{OH} 3}$ values obtained after weighting of the individual values do appear significantly lower than the $\delta_{\mathrm{OH} 4}$ values, except for 5 . Hence, it is again shown that careful consideration of computational data is required to explain the experimental data.

\section{Materials and Methods}

\subsection{NMR Data Acquisition}

NMR data were collected on a Bruker AVIII HD 500 MHz NMR spectrometer (Bruker UK Ltd., Coventry, UK). Samples were shimmed until the $\mathrm{w}_{\frac{1}{2}}$ for the residual $\mathrm{CDCl}_{3}$ solvent signal was $0.5 \mathrm{~Hz}$ or better through a combination of sequential iterations of "TopShim" gradient shimming with additional manual intervention, as required. ${ }^{1} \mathrm{H}$ spectra were collected with $\mathrm{TD}=65,536$ points and $\mathrm{SW}=14 \mathrm{ppm}$ $(\mathrm{o} 1 \mathrm{p}=5.0 \mathrm{ppm})$; zero-filling afforded digital resolution of $0.05 \mathrm{~Hz} /$ point. ${ }^{19} \mathrm{~F}$ spectra were collected with $\mathrm{TD}=262,144$ points and $\mathrm{SW}=50 \mathrm{ppm}$ (o1p proximal to ${ }^{19} \mathrm{~F}$ signal); zero-filling afforded digital resolution of $0.09 \mathrm{~Hz} /$ point. ${ }^{19} \mathrm{~F}\left\{{ }^{1} \mathrm{H}\right\}$ spectra were collected with $\mathrm{TD}=262,144$ points and $\mathrm{SW}=200 \mathrm{ppm}$ (o1p proximal to ${ }^{19} \mathrm{~F}$ signal; inverse-gated decoupling with $\mathrm{o} 2 \mathrm{p}=5.0 \mathrm{ppm}$ ); zero-filling afforded digital resolution of $0.36 \mathrm{~Hz} /$ point. ${ }^{1} \mathrm{H}\left\{{ }^{19} \mathrm{~F}\right\}$ spectra were collected with $\mathrm{TD}=65,536$ points and $\mathrm{SW}=14 \mathrm{ppm}$ $\left(\mathrm{o} 1 \mathrm{p}=5.0 \mathrm{ppm}\right.$; adiabatic inverse-gated decoupling with $\mathrm{o} 2 \mathrm{p}$ proximal to ${ }^{19} \mathrm{~F}$ signal); zero-filling afforded digital resolution of $0.05 \mathrm{~Hz} /$ point. For compound 4, residual molecular sieve particles affected shimming leading to poorer lineshape and resolution $\left(\mathrm{w}_{\frac{1}{2}}\right.$ for residual $\mathrm{CDCl}_{3}$ solvent signal was $1.1 \mathrm{~Hz})$.

\subsection{Quantum Calculations}

All DFT calculations were performed by using the D.01 version of the Gaussian 09 program [27]. We have previously shown, for a series of acyclic fluorohydrins [8], that the experimental trends regarding the variation of ${ }^{\mathrm{h} 1} \mathrm{~J}_{\mathrm{OH} \cdots \mathrm{F}}$ and ${ }^{3} \mathrm{~J}_{\mathrm{OH}-\mathrm{H}}$ can be properly reproduced through quantum calculations using optimized geometries at the PCM/MPWB1K/6-31+G(d,p) level and coupling constants calculated at the B97-2/pcJ-2 level of theory.

Unfortunately, within the current series of levoglucosan derivatives, this methodology appeared to fail and we have therefore selected the following methodology. The conformational landscapes of the levoglucosans have been exhaustively explored at the B97-D3 ${ }^{\mathrm{BJ}} / 6-311++\mathrm{G}(2 \mathrm{~d}, \mathrm{p})$ level of theory 
with investigations around the dihedral angles of the hydroxyl and methoxy groups. This level of theory is, therefore, based, on one hand, on a more extended basis set and, on the other hand, on a dispersion-corrected density functional, B97-D3 ${ }^{\mathrm{BJ}}$, designed for a more accurate description of systems involving noncovalent interactions with dispersion effects. Solvent effects $\left(\mathrm{CHCl}_{3}\right)$ were systematically introduced by means of the polarizable continuum model (PCM) within the integral equation formalism. Frequency calculation of the various energetic minima were then carried out at the same level of theory, allowing the calculations of the corresponding Gibbs free energies, and of the Boltzmann distribution (Equation (1)):

$$
p_{i}=\frac{e^{-\Delta G_{i} / R T}}{\sum_{i} e^{-\Delta G_{i} / R T}},
$$

The spin-spin coupling constants $(J)$ were then estimated from the previous optimized geometries by using the gauge-invariant atomic orbital (GIAO) method. The hybrid B97-2 functional [28] and the pcJ-2 basis set, specifically designed for the calculation of these NMR parameters [29], were used. Again, solvent $\left(\mathrm{CHCl}_{3}\right)$ effects were introduced through the PCM model. Weighted $J$ values were estimated according to their relative populations in $\mathrm{CHCl}_{3}$ at $298 \mathrm{~K}$ and using Equation (2). In addition, the chemical shifts of the hydroxyl hydrogen atoms were computed at the same level of theory and the weighted values were calculated similarly to the coupling constants:

$$
J=\sum_{i} p_{i} J_{(i)}
$$

IMHB interactions were analyzed through AIM topological analysis of the IEF-PCM/B97-D3 ${ }^{\mathrm{BJ}} / 6-311++\mathrm{G}(2 \mathrm{~d}, \mathrm{p})$ wavefunctions with the AIM2000 program [30]. In addition to the electron densities $\rho_{\mathrm{b}}$ and their Laplacians, the potential energy density $V_{\mathrm{b}}$ at the BCP were used to gain additional insights into the strength of a given $\mathrm{HB}[8,25,31-34]$. Indeed, the HB energy can be estimated by using $V_{\mathrm{b}}$ according to the established relationship in Equation (3) [35]:

$$
E_{\mathrm{HB}}=\frac{1}{2} V_{\mathrm{b}}
$$

The complementary contribution of charge transfer between the acceptor lone pair(s) of electrons and the $\sigma^{*}$ donor antibonding orbital was estimated through natural bond orbital (NBO) analyses [36]. The NBO method was applied at the IEF-PCM/B97-D3 ${ }^{\mathrm{BJ}} / 6-311++\mathrm{G}(2 \mathrm{~d}, \mathrm{p})$ level in $\mathrm{CHCl}_{3}$ to provide the corresponding interaction energies $\left(E^{(2)}{ }_{n \rightarrow \sigma^{*}}\right)$ evaluated from second-order perturbation theory, using the NBO 6.0 program [37].

\section{Conclusions}

Intramolecular hydrogen bond features involving $\mathrm{OH} 3$ and $\mathrm{OH} 4$ of a range of levoglucosan analogues were obtained by both experimental (NMR) and theoretical (DFT, AIM, NBO) means. The axial $\mathrm{OH} 4$ group was shown to hydrogen bond with $\mathrm{O} 5$, and this IMHB is perturbed by axial substituents at $\mathrm{C} 2$ : with competing $\mathrm{H}$-bond acceptors (F, OMe) at $\mathrm{C} 2, \mathrm{OH} 4$ engages in a three-center interaction, which can be deduced from the experimentally obtained ${ }^{3} \mathrm{JOH}_{\mathrm{OH}} \mathrm{H}$ coupling constants and interpreted following the rationales introduced by Bernet et al. The axial OH3 is involved in IMHB with $\mathrm{O6}$, and while varying substitution at $\mathrm{C} 2$ and $\mathrm{C} 4$ does not seem to modify the conformation of the six-membered IMHB (as calculated by the very similar dihedral angles), the corresponding ${ }^{3} \mathrm{JOH} 3-\mathrm{H}$ coupling constants do vary significantly. Conformational analysis has shown that, contrary to intuition for such rigid systems, there can be significant rotation around the $\mathrm{C}-\mathrm{OH}$ bond, leading to non-hydrogen bonded conformations being significantly populated. The resulting averaging of the observed coupling constant and chemical shift values therefore hamper straightforward interpretation. The computational study allows to demonstrate that $\mathrm{OH} 3 \cdots \mathrm{O} 6 \mathrm{IMHB}$ are stronger and shorter than 
$\mathrm{OH} 4 \cdots \mathrm{O} 5 \mathrm{IMHB}$, despite the clear preference of $\mathrm{OH} 4$ for $\mathrm{IM} \mathrm{H}$-bonding compared to $\mathrm{OH} 3$, (populations greater than $83 \%$ for $\mathrm{OH} 4$ and range of $50 \%$ to $77 \%$ for $\mathrm{OH} 3$ ). Furthermore, the theoretical data allow emphasizing the contribution of the IMHB populations to the coupling constant and chemical shift variations. Finally, the present work brings clear evidences on the subtle influence of IMHB on hydroxyl group features, both in terms of geometry and electron density parameters. Interestingly, while a ${ }^{\mathrm{h} 1} \mathrm{~J}_{\mathrm{OH} 4 \cdots \mathrm{F}}$ value was measured for both fluorinated substrates, the calculated $\mathrm{OH} \cdots \mathrm{F}$ distance was larger than the sum of their van der Waals radii.

Our results complement and augment the conclusions by Bernet et al., that the weak hydrogen-bond accepting fluorine atom is able to perturb $\mathrm{OH} \cdots \mathrm{O}$ IMHBs, even for fluorination at the levoglucosan C2 position, and that additional substitution modifies this perturbation. However, further to the work of Bernet et al. we show that even for the nominally conformationally rigid levoglucosan systems, conformational analysis and weighting of the theoretical data is important to accurately describe IM H-bonding features. More precisely, weighted coupling constants and chemical shifts are necessary to fully analyze the NMR experimental trends.

Supplementary Materials: The synthesis, characterization and computational data are available online.

Acknowledgments: The EPSRC (EP/K039466/1 (core capability)), the European Community (INTERREG IVa, AI-Chem, project 4494/4196), and the ANR (JCJC "ProOFE" grant (ANR-13-JS08-0007-01), are gratefully acknowledged for their financial support. The current work was granted access to the HPC resources of (CCRT/CINES/IDRIS) under the allocation c2015085117 made by GENCI. We thank the CCIPL for grants of computer time.

Author Contributions: L.Q. and B.L. prepared the levoglucosan derivatives; L.Q., N.J.W., and B.L. performed the NMR experiments in $\mathrm{CDCl}_{3}$ and the measurements of their chemical shifts and coupling constants; E.B. and J.G. performed the corresponding theoretical calculations, with a systematic conformational analysis, topological analysis, and NMR computations; J.-Y.L.Q., J.G., and B.L. analyzed the data and wrote the paper.

Conflicts of Interest: The authors declare no conflict of interest. The founding sponsors had no role in the design of the study; in the collection, analyses, or interpretation of data; in the writing of the manuscript, and in the decision to publish the results.

\section{References}

1. Schneider, H.-J. Hydrogen bonds with fluorine. Studies in solution, in gas phase and by computations, conflicting conclusions from crystallographic analyses. Chem. Sci. 2012, 3, 1381-1394. [CrossRef]

2. Howard, J.A.K.; Hoy, V.J.; O'Hagan, D.; Smith, G.T. How good is fluorine as a hydrogen bond acceptor? Tetrahedron 1996, 52, 12613-12622. [CrossRef]

3. Dunitz, J.D.; Taylor, R. Organic fluorine hardly ever accepts hydrogen bonds. Chem. Eur. J. 1997, 3, 89-98. [CrossRef]

4. Mehta, G.; Sen, S. Probing fluorine interactions in a polyhydroxylated environment: Conservation of a C-F $\cdots$ H-C recognition motif in presence of O-H $\cdots$ O hydrogen bonds. Eur. J. Org. Chem. 2010, 2010, 3387-3394. [CrossRef]

5. Linclau, B.; Golten, S.; Light, M.; Sebban, M.; Oulyadi, H. The conformation of tetrafluorinated methyl galactoside anomers: Crystallographic and NMR studies. Carbohydr. Res. 2011, 346, 1129-1139. [CrossRef] [PubMed]

6. Biamonte, M.A.; Vasella, A. Glycosylidene carbenes part 26. The intramolecular F ... HO hydrogen bond of 1,3-diaxial 3-fluorocyclohexanols. Helv. Chim. Acta 1998, 81, 695-717. [CrossRef]

7. Champagne, P.A.; Desroches, J.; Paquin, J.-F. Organic fluorine as a hydrogen-bond acceptor: Recent examples and applications. Synthesis 2015, 47, 306-322.

8. Linclau, B.; Peron, F.; Bogdan, E.; Wells, N.; Wang, Z.; Compain, G.; Fontenelle, C.Q.; Galland, N.;

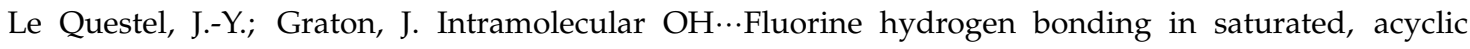
fluorohydrins: The $\gamma$-fluoropropanol motif. Chem. Eur. J. 2015, 21, 17808-17816. [CrossRef] [PubMed]

9. Bernet, B.; Vasella, A. Hydrogen bonding of fluorinated saccharides in solution: F acting as H-bond acceptor in a bifurcated $\mathrm{H}$-bond of 4-fluorinated levoglucosans. Helv. Chim. Acta 2007, 90, 1874-1888. [CrossRef] 
10. Giuffredi, G.T.; Gouverneur, V.; Bernet, B. Intramolecular OH $\cdots$ FC hydrogen bonding in fluorinated carbohydrates: $\mathrm{CHF}$ is a better hydrogen bond acceptor than $\mathrm{CF}_{2}$. Angew. Chem. Int. Ed. 2013, 52, 10524-10528. [CrossRef] [PubMed]

11. Dalvit, C.; Invernizzi, C.; Vulpetti, A. Fluorine as a hydrogen-bond acceptor: Experimental evidence and computational calculations. Chem. Eur. J. 2014, 20, 11058-11068. [CrossRef] [PubMed]

12. Roennols, J.; Manner, S.; Siegbahn, A.; Ellervik, U.; Widmalm, G. Exploration of conformational flexibility and hydrogen bonding of xylosides in different solvents, as a model system for enzyme active site interactions. Org. Biomol. Chem. 2013, 11, 5465-5472. [CrossRef] [PubMed]

13. Graton, J.; Wang, Z.; Brossard, A.-M.; Goncalves Monteiro, D.; Le Questel, J.-Y.; Linclau, B. An unexpected and significantly lower hydrogen-bond-donating capacity of fluorohydrins compared to nonfluorinated alcohols. Angew. Chem. Int. Ed. 2012, 51, 6176-6180. [CrossRef] [PubMed]

14. Laurence, C.; Brameld, K.A.; Graton, J.; Le Questel, J.-Y.; Renault, E. The $\mathrm{p} K_{\mathrm{BHX}}$ database: Toward a better understanding of hydrogen-bond basicity for medicinal chemists. J. Med. Chem. 2009, 52, 4073-4086. [CrossRef] [PubMed]

15. Kuhn, B.; Mohr, P.; Stahl, M. Intramolecular hydrogen bonding in medicinal chemistry. J. Med. Chem. 2010, 53, 2601-2611. [CrossRef] [PubMed]

16. Seib, P.A. 1,6-anhydro-2-deoxy- $\beta$-D-hexopyranoses. J. Chem. Soc. C 1969, 19, 2552-2559. [CrossRef]

17. Sarda, P.; Cabrera Escribano, F.; Alves, R.J.; Olesker, A.; Lukacs, G. Stereospecific access to 2,3,4-trideoxy-2,3,4-trifluoro-D-glucose and D-galactose derivatives. J. Carbohydr. Chem. 1989, 8, 115-123. [CrossRef]

18. Mtashobya, L.; Quiquempoix, L.; Linclau, B. The synthesis of mono- and difluorinated 2,3-dideoxy-D-glucopyranoses. J. Fluorine Chem. 2015, 171, 92-96. [CrossRef]

19. Wollwage, P.C.; Seib, P.A. Thermal degradation of 2-O-methylcellulose. Carbohydr. Res. 1969, 10, 589-594. [CrossRef]

20. Hori, H.; Nishida, Y.; Ohrui, H.; Meguro, H. Regioselective de-O-benzylation with lewis acids. J. Org. Chem. 1989, 54, 1346-1353. [CrossRef]

21. Pacak, J.; Podesva, J.; Tocik, Z.; Cerny, M. Syntheses with anhydro sugars. XI. Preparation of 2-deoxy-fluoro-D-glucose and 2,4-dideoxy-2,4-difluoro-D-glucose. Collect. Czech. Chem. Commun. 1972, 37, 2589-2599. [CrossRef]

22. Barford, A.D.; Foster, A.B.; Westwood, J.H.; Hall, L.D.; Johnson, R.N. Fluorinated carbohydrates. Carbohydr. Res. 1971, 19, 49-61. [CrossRef]

23. Cormanich, R.A.; Freitas, M.P.; Tormena, C.F.; Rittner, R. The F $\cdots$ HO intramolecular hydrogen bond forming five-membered rings hardly appear in monocyclic organofluorine compounds. RSC Adv. 2012, 2, 4169-4174. [CrossRef]

24. Cormanich, R.A.; Rittner, R.; Freitas, M.P.; Buhl, M. The seeming lack of CF...HO intramolecular hydrogen bonds in linear aliphatic fluoroalcohols in solution. Phys. Chem. Chem. Phys. 2014, 16, 19212-19217. [CrossRef] [PubMed]

25. Graton, J.; Compain, G.; Besseau, F.; Bogdan, E.; Watts, J.M.; Mtashobya, L.; Wang, Z.; Weymouth-Wilson, A.; Galland, N.; Le Questel, J.-Y.; et al. Influence of alcohol $\beta$-fluorination on hydrogen-bond acidity of conformationally flexible substrates. Chem. Eur. J. 2017, 23, 2811-2819. [CrossRef] [PubMed]

26. Bondi, A. Van der waals volumes and radii. J. Phys. Chem. 1964, 68, 441-451. [CrossRef]

27. Frisch, M.J.; Trucks, G.W.; Schlegel, H.B.; Scuseria, G.E.; Robb, M.A.; Cheeseman, J.R.; Scalmani, G.; Barone, V.; Mennucci, B.; Petersson, G.A.; et al. Gaussian 09; Revision D.01; Gaussian, Inc.: Wallingford, CT, USA, 2009.

28. Wilson, P.J.; Bradley, T.J.; Tozer, D.J. Hybrid exchange-correlation functional determined from thermochemical data and ab initio potentials. J. Chem. Phys. 2001, 115, 9233-9242. [CrossRef]

29. Jensen, F. The basis set convergence of spin-spin coupling constants calculated by density functional methods. J. Chem. Theory Comput. 2006, 2, 1360-1369. [CrossRef] [PubMed]

30. Biegler-Koenig, F.W.; Schonbohm, J.; Bayles, D. AIM2000-A program to analyze and visualize atoms in molecules. J. Comput. Chem. 2001, 22, 545-559.

31. Espinosa, E.; Lecomte, C.; Molins, E. Experimental electron density overlapping in hydrogen bonds: Topology vs. energetics. Chem. Phys. Lett. 1999, 300, 745-748. [CrossRef]

32. Abramov, Y.A. On the possibility of kinetic energy density evaluation from the experimental electron-density distribution. Acta Cryst. A 1997, A53, 264-272. [CrossRef] 
33. Bogdan, E.; Compain, G.; Mtashobya, L.; Le Questel, J.-Y.; Besseau, F.; Galland, N.; Linclau, B.; Graton, J. Influence of fluorination on the conformational properties and hydrogen-bond acidity of benzyl alcohol derivatives. Chem. Eur. J. 2015, 21, 11462-11474. [CrossRef] [PubMed]

34. Bogdan, E.; Quarré de Verneuil, A.; Besseau, F.; Compain, G.; Linclau, B.; Le Questel, J.-Y.; Graton, J. $\alpha$-fluoro-o-cresols: The key role of intramolecular hydrogen bonding in conformational preference and hydrogen-bond acidity. ChemPhysChem 2016, 17, 2702-2709. [CrossRef] [PubMed]

35. Espinosa, E.; Molins, E.; Lecomte, C. Hydrogen bond strengths revealed by topological analyses of experimentally observed electron densities. Chem. Phys. Lett. 1998, 285, 170-173. [CrossRef]

36. Weinhold, F.; Landis, C.R. Valency and Bonding: A Natural Bond Orbital Donor-Acceptor Perspective; Cambridge University Press: Cambridge, UK, 2005.

37. Glendening, E.D.; Badenhoop, J.K.; Reed, A.E.; Carpenter, J.E.; Bohmann, J.A.; Morales, C.M.; Landis, C.R.; Weinhold, F. Natural Bond Orbital (NBO) Version 6.0; Theoretical Chemistry Institute: Madison, WI, USA, 2013.

Sample Availability: Samples of the compounds are not available from the authors.

(c) 2017 by the authors. Licensee MDPI, Basel, Switzerland. This article is an open access article distributed under the terms and conditions of the Creative Commons Attribution (CC BY) license (http:/ / creativecommons.org/licenses/by/4.0/). 